\title{
The Sense of Coherence in the Salutogenic Model of Health
}

\author{
Monica Eriksson
}

\section{Introduction}

The aim of this section is to shortly describe the theoretical framework of salutogenesis with a special focus on the key concepts, the sense of coherence and the generalized and specific resistance resources. This chapter begins with reflection on the ontological and epistemological background of salutogenesis, which is not particularly described and explained to any significant extent in the publications by Antonovsky (1979, 1987). More recent research on this theme is scarce. Next, health as a process is described by starting from Antonovsky's definition of salutogenesis as a movement toward the health end of a health continuum. The chapter ends with some evidence of how the sense of coherence impacts health and well-being.

\section{The Ontological Background}

Ontology is the study of reality (Heil, 2005). What do we know about the ontological background of salutogenesis? In his second book, Unraveling the Mystery of Health (1987), Antonovsky described how he perceived the world. Two important things stand: (1) he saw man in interaction with his environment and (2) chaos and change is a normal state of life. The former calls for system theory thinking where the focus is on the individual in a context (Antonovsky, 1985). By the latter, he perceived daily life as constantly changing; a heterostatic as opposed to a homeostatic state. For the individual, the challenge is to manage the chaos and find strategies and resources available for coping with the changes in everyday life. As a medical sociologist, this was

\footnotetext{
M. Eriksson (ه)

Department of Health Sciences, Section of Health Promotion and Care Sciences, Center on Salutogenesis, University West, Gustava Mellins gata 2, Trollhättan SE-46186, Sweden

e-mail: monica.eriksson@hv.se
}

a natural way for Antonovsky to perceive the world: seeing humans as part of a larger context.

In the beginning of the 1990s, Aaron Antonovsky published an article about the six Cs: complexity, conflict, chaos, coherence, coercion, and civility (Fig. 11.1). Here, he expressed how he looked at society and the human being in that context (Antonovsky, 1993a). As a medical sociologist, he distinctly expressed systems theory thinking. He saw the individual in interaction with the environment and context. He stressed that the salutogenic theory and its key concept, sense of coherence, can be applied at a collective level, and not only with a focus on the individual level.

Complexity, according to Antonovsky, related to how a system is organized:

\begin{abstract}
Complexity refers to the level of organisation of a system. This level both sets the problems and provides the potential, interacting with sub and suprasystem, for the system to maintain a dynamic steady state. Such a steady state is one way of defining health. (Antonovsky, 1993a, s. 969)
\end{abstract}

Complexity may lead to conflicts, the greater the complexity, the deeper the conflicts. He especially mentioned conflict between civilizations:

\section{Conflict refers to internal tensions of the human being, to tensions between persons, to tensions between the individual and the suprasystems of which she or he is a part, and to tensions between or among such suprasystems. (Antonovsky, 1993a, s. 970)}

Complexity also offers opportunities for different and flexible choices, possibilities for adapting to change, and possibilities for systems (communities) to reorganize themselves. Conflict leads to tension; therefore, it will be crucial for the community how we can deal with this tension and avoid stress. Chaos can be exemplified as violence and war, and the image of young men and women equipped with weapons, trying to solve conflicts with even more violence, a senseless and unpredictable violence (Antonovsky, 1993a, p. 972). The difficulties in resolving conflicts go from a societal level to the group level, to families torn apart, and 


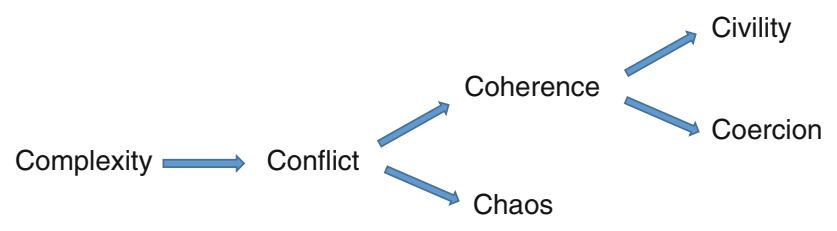

Fig. 11.1 The six $\mathrm{Cs}$ - an ontological perspective on salutogenesis. After Antonovsky, 1993a, p. 969. Published with permission from the copyright holder and Social Science and Medicine

where children, women, and the elderly are particularly vulnerable. As opposed to this chaos, Antonovsky raised another way to go, to coherence. Sense of coherence is the term he introduced as an opportunity to manage and adapt to a life of chaos. Two important dimensions in Fig. 11.1 remain to be explained: civility and coercion.

Civility is one of the basic values of salutogenesis, a value that informs how we relate to other people, how we look at them as either people with different strengths and abilities, or people with flaws and shortcomings. Civility is about respect toward other people and about the humanity we communicate. Antonovsky discussed humanity and values in terms of respect toward other people, or to used his own words, "The key lies in a society and in people who cares about each other" (Antonovsky, 1993c, p. 2). The opposite of civility and respect is coercion. A society based on respect for people also requires restrictions against domination, oppression, and poverty (Antonovsky, 1993a, p. 973). More recent research in the salutogenic field highlights a new concept of reasonableness (Boström, Kaplan, \& Kaplan, 2014; Kaplan \& Kaplan, 2003, 2011), which brings together the supporting factors in the environment of perceived health and well-being in a particular model, The Reasonable Person Model. Kaplan and Kaplan (2003) describe how people are more respectful, cooperative and more contented in situations where the environment supports their basic information needs. The model focuses on how people are interdependent. It emphasizes three dimensions that contribute to civility, namely a curiosity to explore and understand, meaningful activities, and recovery. The concept of reasonableness has similarities with the dimensions of the sense of coherence: comprehensibility, meaningfulness, and manageability.

\section{The Epistemological Background}

Epistemology is the study of knowledge (Audi, 2011). Going back to Antonovsky's two books Health, Stress and Coping and Unraveling the Mystery of Health, one can find little insight into how he considered knowledge and learning. As far as this author knows, he did not manifest an epistemological basis for salutogenesis, neither describing his view of how knowledge in general arises, nor how learning is meaningful in the salutogenic framework. It appears that he was preoccupied with examining and describing how a strong sense of coherence may have an impact on perceived health. A search in different databases provides little response. Yet others have focused on knowledge and learning aspects of salutogenesis, related for example to the education of children with special needs (Lindström, 1999 ) and to children with learning difficulties (Lackaye \& Margalit, 2006; Margalit \& Efrati, 1996).

More generally, Nilsson and Lindström (1998) describe how learning can be considered a health promotion process, not only to learn about health, but that the learning process also promotes health. By combining educational theories and salutogenesis, they describe 'the salutogenic school' (Antonovsky, 1993c, p. 5), achieved by creating meaningful learning situations, clear structures for curricula and the school work, with dedicated teachers supporting each other and the students, and being role models.

Boström and Lassen (2006) point out the importance of giving space for individual ways of learning and different learning strategies. Individual learning styles create opportunities for students to find meaning in school. A new concept that describes learning as a health promotion process is 'healthy learning' (Lindström \& Eriksson, 2011). It means to move on from traditional health education, through to increased health awareness (health literacy), and on to learning which actually promotes health (Lindström \& Eriksson, 2011; Quennerstedt, 2006; Quennerstedt, Burrows, \& Maivorsdotter, 2010). As an example, the curriculum for health education in Australia has recently been revised and now adopts a strength-based (salutogenic) approach (Macdonald, 2013; McCuaig, Quennerstedt, \& Macdonald, 2013). The curriculum focuses on promoting sound health habits, instead of the earlier focus on avoiding health risks. Health is understood as a multidimensional concept including physical, social, mental, and spiritual health. Health is regarded as a lifelong dynamic process with people as active participants in a context. Finally, health is seen not as an end in itself but as a means to live a good life (McCuaig et al., 2013, p. 113). As another example, from Germany, an attempt to apply salutogenesis didactically in education is the 'team ombuds model' - $\mathrm{tOm}$ (Mayer \& Boness, 2011), developed to promote the sense of coherence and cross-cultural competence among students and teachers.

Epistemologically, salutogenesis can be conceived as a constant learning process (Fig. 11.2) supporting movement toward health (and other desired aspects of one's existence) via improving health literacy: knowledge supports health literacy, which supports development in the ways one relates to one's world. The process of relating to others produces learning, and the knowledge gained from practice expands 
one's area of knowledge. In the course of daily life, this integrated learning process is continuous.

\section{Health as a Process}

According to Antonovsky, health is movement on a continuum of ease and dis-ease (Antonovsky, 1993b). He referred to the ability to comprehend the whole situation, and the capacity to use the resources available, as the sense of coherence. This capacity was a combination of peoples' ability to assess and understand the situation they were in, to find a meaning to move in a health promoting direction, also having the capacity to do so- that is, comprehensibility, meaningfulness, and the manageability, to use Antonovsky's own terms (Lindström \& Eriksson, 2005). In such an approach, no one is categorized as healthy or diseased. Since we are all somewhere between the imaginary poles of total wellness and total illness, the whole population becomes the focus of concern. Even the fully robust,

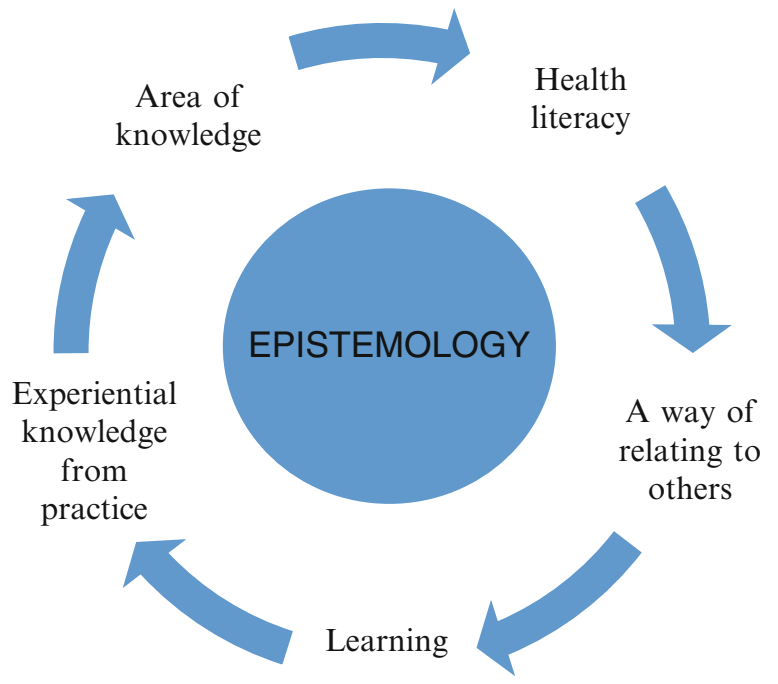

Fig. 11.2 Salutogenesis from an epistemological perspective energetic, symptom-free, richly functioning individual has the mark of mortality: he or she wears glasses, has moments of depression, comes down with flu, and may also have as yet non-detectable malignant cells. Even the terminal patient's brain and emotions may be fully functional. The great majority of us are somewhere between the two poles. Priority in health service is justly given to those at the sicker end of the continuum. But in our thinking and our research, we should ask: "How does a person-wherever he or she is on the continuum-move toward the healthy pole?" (Sagy, Eriksson, \& Braun-Lewensohn, 2015). The idea of movement along an ease/dis-ease continuum is illustrated in Fig. 11.3.

Antonovsky assumed that we constantly are exposed to changes and events that may be considered as stressors. This may involve major life events such as when someone in the family falls ill, changes in the family (e.g., a divorce), or changes in the workplace (organizational changes or unemployment). Previous research shows that such major life events affect health (Folkman, 1984). They can reduce health temporarily but can also in the longer term strengthen us in a way that makes it possible for us to manage stress. The negative life events have even given us experiences that can be used in other similar situations.

Antonovsky discussed the theories behind stress and coping extensively. He particularly rejected the thoughts behind Lazarus' cognitive theory on stress and coping as well as theories of life event (Lazarus \& Folkman, 1984). According to Antonovsky, the assumption behind these theories was a life in balance, that is, a homeostatic life. A disturbance was assumed to damage the balance and damage health and wellbeing, that is, a pathogenic view of life. Furthermore, the traditional theories on stress and coping are mainly focused on the concept of control. In salutogenesis, the emphasis is on the person's ability to use generalized resistance resources, both internal and external, at disposal to manage ubiquitous stressful situations. The actual starting point, according to Antonovsky, is that life is a chaos in which we must constantly relate to change. It becomes vital how
Fig. 11.3 The ease/dis-ease continuum (Antonovsky, 1979, 1987). Graphic: Bengt Lindström, Monica Eriksson, Peter Wikström (Lindström \& Eriksson, 2010)

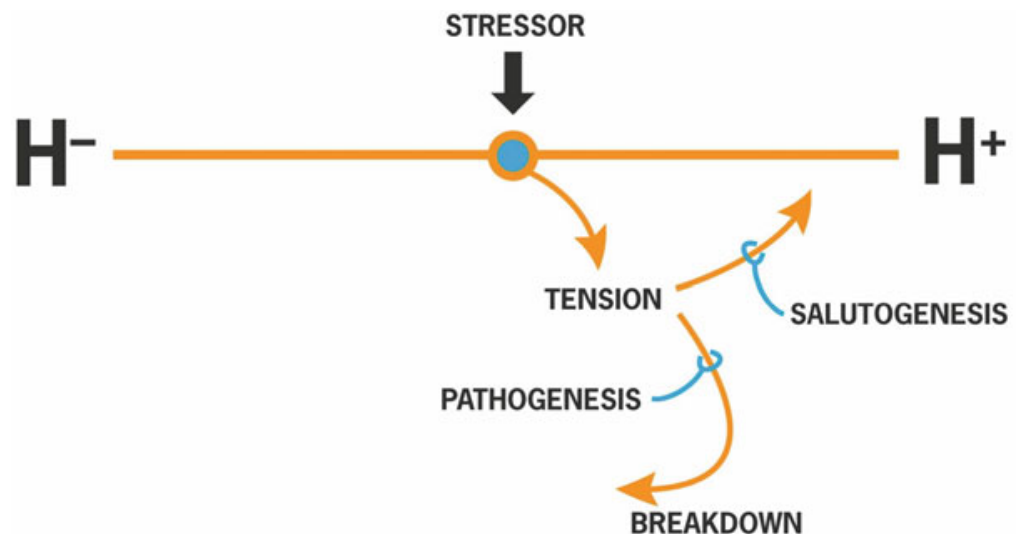




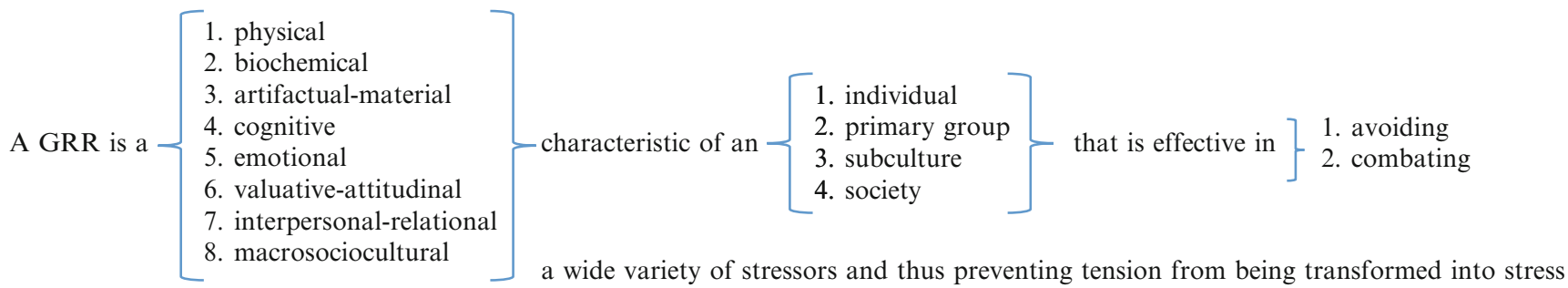

Fig. 11.4 The definition of generalized resistance resources (Antonovsky, 1979, s. 103)

we are able to manage this chaos. This is the salutogenic view of stress and coping, according to Antonovsky:

... life is inherently full of stressors, with life-situation stressor complexes by far deserving most of our attention of we wish to understand either health or disease. Focusing on health, I expressly rejected the implicit assumption that stressors are inherently pathogenic. Their health consequences can only be understood if we understand the coping process. (Antonovsky, 1992, p. 48)

Three potential reactions and outcomes of stress are (1) being neutral against the stressors, (2) being able to manage stress for the movement toward the health end, and (3) being unable to manage stress which leads to a breakdown expressed in terms of diseases and death (Antonovsky, 1987). In the case of events that do not concern us as much, that is, daily hassles to use the words by Antonovsky (1987), we can remain neutral to them, since they do not affect health in any significant way. However, if it is a question of events that we cannot manage, we become ill, or we to mobilize internal and/or external resources around us, allowing us to deal with what happened and move in the direction of health.

\section{Generalized and Specific Resistance Resources}

Along with the sense of coherence, a key concept in the salutogenic model is resistance resources (Antonovsky, 1979, 1987), including generalized resources (potentially available for engagement in a wide range of circumstances) and specialized resources (particular resources relevant to particular circumstances). Since the subject of resistance resources is dealt with in detail in several chapters in Part II of this book, only a few comments are offered here, with special attention to the relevance of resistance resources to the main subject of this Section: the sense of coherence.

Generalized resistance resources are the cornerstones in the development of a strong sense of coherence. They are of a different nature: genetic and constitutional, psychosocial, cultural and spiritual, material... and a preventive health orientation (Lindström \& Eriksson, 2005). Resistance resources exist at the individual, the group (family), the subculture and the whole society levels (Antonovsky,
1979, p. 103). Antonovsky's formal definition of generalized resistance resources is given in Fig. 11.4.

Research on the role of generalized resistance resources in building the sense of coherence is scarce. Early research (Antonovsky, 1991, cited in Sagy \& Antonovsky, 1999, p. 256) showed that three factors seemed to be particularly important for developing a strong sense of coherence: consistency, balance between under- and over-load and the opportunity to participate in decision making affect one's situation. The question of which resistance resources are involved in building the sense of coherence has received some attention, as for example in these:

- A Finnish study examined the importance of generalized resistance resources such as cognitive ability, marital status, level of family income, the length of formal education and physical activity for the development of a strong sense of coherence among Finns aged 65-69 years (Read, Aunola, Feldt, Leinonen, \& Ruoppila, 2005). The results showed that cognitive ability and physical activity were related to the sense of coherence, which in turn was associated with good social and mental health.

- A qualitative Swedish study of caregivers to older adults aimed to illuminate generalized and specific resistance resources against caregiver stress; it identified the panoply of negative and positive experiences of caring for a relative as a particularly salient resource'caregivinghood,' as in the sense of 'parenthood' (Wennerberg, Lundgren, \& Danielson, 2012).

- Through a thematic analysis of the work by Antonovsky and more recent research Griffiths, Ryan, and Foster (2011, p. 170) identified 15 general resistant resource themes (1) structure in life, (2) predictability in life, (3) social support, (4) coping strategies, (5) life meaning, (6) responsibility, (7) comprehension, (8) expression of confidence, (9) challenges worth investing time and effort, (10) health/illness, (11) future orientation, (12) past orientation, (13) positive, solution focused outlook, (14) emotional connection, and (15) ensuring that you are justly treated. No resource related theme emerged that did not fit the sense of coherence concept. 


\section{Sense of Coherence}

Antonovsky initiated a study among different ethnic groups of women in Israel with the aim to investigate their menopausal symptoms, that is, a traditional epidemiological study from a risk perspective (Antonovsky, 1987). He interviewed them about perceived health, and also about various life events affecting them, such as losing their eyesight, loss of husband/wife, amputation of the leg/arm or to have suffered a serious illness (Antonovsky, 1983). After analyzing the interviews, he found that $29 \%$ of the women reported good health, although they survived the Holocaust. Antonovsky raised the question of how it could be possible that women may experience good health despite the fact that they experienced such a difficult trauma as the Holocaust. It led him to focus on this small number of respondents, and a search for their health resources. This was the start of Antonovsky's personal paradigm shift from pathogenesis to salutogenesis.

Based on the interviews with the Israeli women, an important factor emerged: the sense of coherence. The sense of coherence reflects a person's view of life and capacity to respond to stressful situations. It is a global orientation to view life as structured, manageable, and meaningful. It is a personal way of thinking, being and acting, with an inner trust, which leads people to identify, benefit, use, and re-use the resources at their disposal (Eriksson \& Lindström, 2006). Sense of coherence consists of three elements: comprehensibility, manageability, and meaningfulness. The original definition by Antonovsky (1987) is as follows:

\section{a global orientation that expresses the extent to which one has a pervasive, enduring though dynamic feeling of confidence that (1) the stimuli from one's internal and external environments in the course of living are structured, predictable, and explicable; (2) the resources are available to one to meet the demands posed by these stimuli; and (3) these demands are challenges, worthy of investment and engagement. (p. 19)}

It is also about one's own ability to identify one's internal and external resources and use them in a way that promotes health and well-being (Eriksson \& Lindström, 2006). Further, it is a way of thinking in terms of peoples' resources, and even a way to work, to meet and treat other people. According to Antonovsky, sense of coherence is a life orientation. Koltko-Rivera (2004) defines life orientation as follows:

... a way of describing the universe and life within it, both in terms of what is and what ought to be. A given worldview is a set of beliefs that includes limiting statements and assumptions regarding what exists and what does not.... A worldview defines what can be known or done in the world, and how it can be known or done. ... What goals can be sought in life ... defines what goals should be pursued. (Koltko-Rivera, 2004, p. 4)
It is to the nature of the life orientation that is termed 'the sense of coherence' that this Part of the book is devoted. Inevitably, the sense of coherence is also a theme, major or minor, in virtually every chapter of this book. The sense of coherence was Antonovsky's main interest in his study of salutogenesis, even if he encouraged research on all aspects of the salutogenic model. Following Antonovsky's wholehearted lead, succeeding generations of scholars have focused so much on the study of the sense of coherence that the salutogenic model is sometimes referred to as the 'sense of coherence theory.' While Antonovsky did not himself define sense of coherence as a theory, it was his answer to the salutogenic question: what are the origins of health? He encouraged a search for other answers, but as this book reveals, most salutogenesis researchers have chosen to follow the path to the sense of coherence, the path that Antonovsky himself so doggedly trod.

Open Access This chapter is distributed under the terms of the Creative Commons Attribution-Noncommercial 2.5 License (http:// creativecommons.org/licenses/by-nc/2.5/) which permits any noncommercial use, distribution, and reproduction in any medium, provided the original author(s) and source are credited.

The images or other third party material in this chapter are included in the work's Creative Commons license, unless indicated otherwise in the credit line; if such material is not included in the work's Creative Commons license and the respective action is not permitted by statutory regulation, users will need to obtain permission from the license holder to duplicate, adapt or reproduce the material.

\section{References}

Antonovsky, A. (1979). Health, stress and coping. San Francisco: Jossey-Bass.

Antonovsky, A. (1983). The sense of coherence: Development of a research instrument. Newsletter Research Report. Schwartz Research Center for behavioral medicine, Tel Aviv University, Vol. 1: pp. 11-22.

Antonovsky, A. (1985). The life cycle, mental health and the sense of coherence. Israel Journal of Psychiatry \& Related Sciences, 22(4), 273-280.

Antonovsky, A. (1987). Unraveling the Mystery of Health. How people manage stress and stay well. San Francisco: Jossey-Bass.

Antonovsky, A. (1991). The structural resources of salutogenic strengths. In C. L. Cooper \& R. Payne (Eds.), Personality and stress: Individual differences in the stress process. New York: L. Wiley.

Antonovsky, A. (1992). Can attitudes contribute to health? Advances, The Journal of Mind-Body Health, 8(4), 33-49.

Antonovsky, A. (1993a). Complexity, conflict, chaos, coherence, coercion and civility. Social Science \& Medicine, 37(8), 969-981.

Antonovsky, A. (1993b). The structure and properties of the sense of coherence scale. Social Science \& Medicine, 36(6), 725-733.

Antonovsky, A. (1993c). Some salutogenic words of wisdom to the conferees. NHV, Göteborg. [Electronic] http://www.angelfire. com/ok/soc/agoteborg.html

Audi, R. (2011). Epistemology. A contemporary introduction to the theory of knowledge. New York: Routledge. 
Boström, A., Kaplan, R., \& Kaplan, S. (2014). Creating supportive environments to foster reasonableness and achieve sustainable well-being. In T. J. Hämäläinen \& J. Michaelson (Eds.), Wellbeing and beyond. Broadening the public and policy discourse. Cheltenham: Edward Elgar.

Boström, L., \& Lassen, L. M. (2006). Unraveling learning, learning styles, learning strategies and meta-cognition. Education \& Training, 48(2/3), 178-189.

Eriksson, M., \& Lindström, B. (2006). Antonovsky's Sense of Coherence Scale and the relation with health: A systematic review. Journal of Epidemiology \& Community Health, 60(5), 376-381.

Folkman, S. (1984). Personal control and stress and coping processes: A theoretical anallysis. Journal of Personality and Social Psychology, 46(4), 839-852.

Griffiths, C. A., Ryan, P., \& Foster, J. H. (2011). Thematic analysis of Antonovsky's sense of coherence theory. Scandinavian Journal of Psychology, 52, 168-173.

Heil, J. (2005). From an ontological point of view. Gloucestershire: Clarendon.

Kaplan, S., \& Kaplan, R. (2003). Health, supportive environments, and the reasonable person model. American Journal of Public Health, 93, 1484-1489.

Kaplan, R., \& Kaplan, S. (2011). Well-being, reasonableness, and the natural environment. Applied Psychology: Health and Well-Being, 3(3), 304-321.

Koltko-Rivera, M. E. (2004). The psychology of worldviews. Review of General Psychology, 8, 3-58.

Lackaye, T. D., \& Margalit, M. (2006). Comparisons of achievement, effort, and self-perceptions among students with learning disabilities and their peers from different achievement groups. Journal of Learning Disabilities, 39(5), 432-446.

Lazarus, R., \& Folkman, S. (1984). Stress, appraisal and coping. New York: Springer.

Lindström, B. (1999). The salutogenic model as a tool for quality of life enhancement for children with special needs. Exceptionality Education Canada, 9(1/2), 105-109.

Lindström, B., \& Eriksson, M. (2005). Salutogenesis. Journal of Epidemiology and Community Health, 59(6), 440-442.

Lindström, B., \& Eriksson, M. (2010). The hitchhiker's guide to salutogenesis: Salutogenic pathways to health promotion. The IUHPE Global Working Group on Salutogenesis. Helsinki: Folkhälsan research center, Health promotion research, Research report: 2010:2.
Lindström, B., \& Eriksson, M. (2011). From health education to healthy learning: Implementing salutogenesis in educational science. Scandinavian Journal of Public Health, 39(Suppl 6), 85-92.

Macdonald, D. (2013). The new Australian Health and Physical Education Curriculum: A case of/for gradualism in curriculum reform? Asia-Pacific Journal of Health, Sport and Physical Education, 4(2), 95-108.

Margalit, M., \& Efrati, M. (1996). Loneliness, coherence and companionship among children with learning disorder. Educational Psychology, 16(1), 69-80.

Mayer, C.-H., \& Boness, C. (2011). Interventions to promoting sense of coherence and transcultural competences in educational contexts. International Review of Psychiatry, 23(6), 516-524.

McCuaig, L., Quennerstedt, M., \& Macdonald, D. (2013). A salutogenic, strengths-based approach as a theory to guide HPE curriculum change. Asia-Pacific Journal of Health, Sport and Physical Education, 4(2), 109-125.

Nilsson, L., \& Lindström, B. (1998). Learning as a health promoting process: The salutogenic interpretation of the Swedish cirricula in state education. Internet Journal of Health Promotion. [Elektronic]. http://www.diva-portal.org/smash/record.jsf?searchId=2\& pid=diva2:696903

Quennerstedt, M. (2006). Learning health. [Doctoral thesis]. Örebro: Örebro University.

Quennerstedt, M., Burrows, L., \& Maivorsdotter, N. (2010). From teaching young people to be healthy to learning health. Utbildning \& Demokrati, 19(2), 97-112.

Read, S., Aunola, K., Feldt, T., Leinonen, R., \& Ruoppila, I. (2005). The relationship between Generalizes Resistance Resources, Sense of Coherence, and health among Finnish people aged 65-69. European Psychologist, 10(3), 244-253.

Sagy, S., \& Antonovsky, H. (1999). Factors related to the development of the sense of coherence (sense of coherence) in adolescents. A retrospective study. Polish Psychological Bulletin, 30(4), 255-262.

Sagy, S., Eriksson, M., \& Braun-Lewensohn, O. (2015). The salutogenic paradigm. In S. Joseph (Ed.), Positive psychology in practice: Promoting human flourishing in work, health, education, and everyday life (2nd ed., pp. 61-80). New York: Wiley.

Wennerberg, M. M. T., Lundgren, S. M., \& Danielson, E. (2012). Using the salutogenic approach to unravel informal caregivers' resources to health: Theory and methodology. Aging \& Mental Health, 16(3), 391-402. 